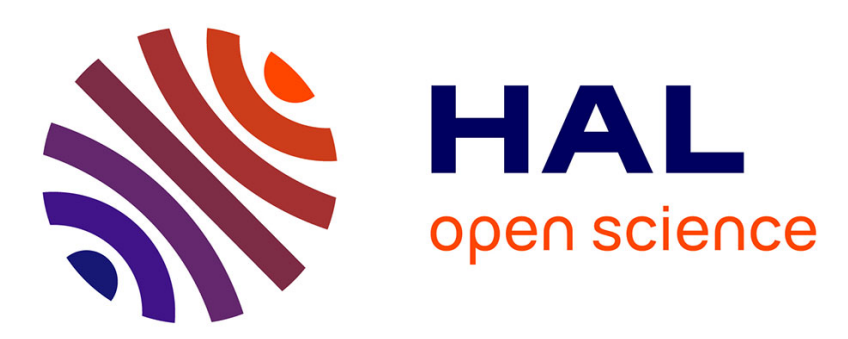

\title{
Measuring potential gains from specialization under non-convex technologies
}

Stéphane Blancard, Jean-Philippe Boussemart, Hervé Leleu, . School of Management, . Umr 8179 Lem

\section{To cite this version:}

Stéphane Blancard, Jean-Philippe Boussemart, Hervé Leleu, . School of Management, . Umr 8179

Lem. Measuring potential gains from specialization under non-convex technologies. 2009. hal02819214

\section{HAL Id: hal-02819214 \\ https://hal.inrae.fr/hal-02819214}

Preprint submitted on 6 Jun 2020

HAL is a multi-disciplinary open access archive for the deposit and dissemination of scientific research documents, whether they are published or not. The documents may come from teaching and research institutions in France or abroad, or from public or private research centers.
L'archive ouverte pluridisciplinaire HAL, est destinée au dépôt et à la diffusion de documents scientifiques de niveau recherche, publiés ou non, émanant des établissements d'enseignement et de recherche français ou étrangers, des laboratoires publics ou privés. 
March 2009

\section{WORKING PAPER SERIES \\ 2009-ECO-02}

\section{Measuring potential gains from specialization under non-convex technologies}

Stéphane Blancard

ENESAD, UMR CESAER

Jean-Philippe Boussemart

University of Lille, IÉSEG School of Management, CNRS-LEM (UMR 8179)

Hervé Leleu

CNRS-LEM (UMR 8179), IÉSEG School of Management

IÉSEG School of Management

Catholic University of Lille

3 , rue de la Digue

F-59000 Lille

www.ieseg.fr

Tel: $33(0) 320545892$

Fax: 33(0)320 574855 


\title{
Measuring potential gains from specialization under non-convex technologies*
}

\author{
Stéphane Blancard ${ }^{\dagger}$ \\ ENESAD, UMR CESAER, \\ 26 Boulevard Dr Petitjean, B.P. 87999, F-21000 Dijon, France. \\ Email: stephane.blancard@enesad.inra.fr \\ Jean-Philippe Boussemart \\ University of Lille, IÉSEG School of Management, LEM-CNRS, \\ 3 rue de la Digue, 59000 Lille, France. \\ Email: jp.boussemart@ieseg.fr
}

\section{Hervé Leleu}

CNRS-LEM and IÉSEG School of Management,

3 rue de la Digue, 59000 Lille, France.

Email: h.leleu@ieseg.fr

\footnotetext{
* This research has been supported by the "Agence Nationale de la Recherche" on the project "Popsy : Arable Crop Production, Environment and Regulation", decision n ${ }^{\circ}$ ANR-08-STRA-12-05. We use a database of Centre d'Economie Rurale de La Meuse financed as part of an agreement with INRA.

${ }^{\dagger}$ Corresponding author.
} 


\title{
Measuring potential gains from specialization under non-convex technologies
}

\begin{abstract}
:
In this paper, the Free Coordination Hull (FCH) approach developed by Green and Cook (2004) is combined with the Free Disposal Hull (FDH) model to detect potential gains from specialization. As a non-convex approach that allows both directly observed and summed decision making units (DMUs) to define the production technology, FCH is the relevant model for analyzing optimal reapportionment of activity among smaller and more specialized units. Indeed the convexity assumption in more traditional Data Envelopment Analysis (DEA) models precludes the possibility of detecting potential gains from specialization and can only reveal economies of scope. Therefore non-convex technologies are required to model diseconomies of scope. Based on FDH and FCH technologies, an overall efficiency measure is decomposed into three components, namely technical, size and specialization efficiencies. A database of French farms for the year 2003 is used for illustration. Results indicate that input inefficiency in the agricultural sector is driven mainly by lack of specialization, which represents about $50 \%$ of overall inefficiency.
\end{abstract}

Keywords: specialization; free coordination hull; free disposal hull; agriculture

\section{Résumé :}

Dans ce travail, l'approche développée par Green and Cook (2004) pour modéliser une technologie de production (dénommée Free Coordination Hull, FCH) est combinée avec le modèle de libre disposition (Free Disposal Hull, FDH) pour détecter des gains potentiels à la spécialisation. Le modèle FCH définit une technologie de production non convexe qui ajoute à la libre disposition des inputs et des outputs l'hypothèse d'additivité des plans de production observés. Il est donc le candidat naturel pour mesurer l'intérêt de répartir la production d'une firme entre plusieurs autres firmes de pllus petites tailles et plus spécialisées. En effet, cette possibilité n'est pas permise par les modèles plus traditionnels comme les modèles Data Envelopment Analysis (DEA) qui reposent sur une hypothèse de convexité et ne peuvent donc révéler que des économies de gamme. Sur la base d'une comparaison des modèles FDH et FCH une mesure globale d'efficacité est décomposée en trois composantes à savoir l'efficacité technique, l'efficacité taille et les gains potentiels à la spécialisation. Une base de données sur des exploitations agricoles françaises en 2003 sert d'illustration aux mesures développées. Les résultats montrent que près de la moitié l'inefficacité mesurée dans le secteur étudié est liée au manque de spécialisation des exploitations.

Mots-Clés : specialisation ; free coordination hull; free disposal hull; agriculture 


\section{Introduction}

In a recent paper, Green and Cook (2004) (hereafter GC) proposed an alternative nonparametric approach to assess the performance of a decision making unit (DMU). They built the frontier not only with individual DMUs but also with synthetic DMUs resulting from the summation of observed DMUs. This production possibility set (pps) is called the Free Coordination Hull $(\mathrm{FCH})$ in reference to the Free Disposal Hull (FDH) model introduced by Deprins et al. (1984). GC briefly emphasized the interest of this methodology for units which wish to improve their efficiency by reorganizing their activities. Thus, they partly conclude their paper by: “... if observed DMU C is dominated by $D M U A+B$ then it seems reasonable to consider whether $C$ could achieve efficiency gains by reorganizing its activities in some way (p. 1062).” This paves the way for measuring the gains from specialization.

Starting from this conclusion, we intend to confirm the operational thrust of their approach by analysing how activities could be optimally apportioned among a number of smaller DMUs. The notion of specialization and its associated gains are derived from the classical concept of economies of scope introduced by Panzar and Willig (1981) and Baumol et al. (1982). They defined economies of scope as cost reductions made possible by joint production instead of separated production. In opposition to economies of scope, diseconomies of scope or specialization gains prevail if the reapportionment of production into smaller units is cheaper than joint production. Since mergers and acquisitions occurred in many industries, most published cases have mainly examined cost reductions due to diversification as the only possible reorganization of activities. Among others, Färe (1986), Grosskopf and Yaisawarng (1990), and, more recently, Bogetoft and Wang (2005) have used a nonparametric approach assuming a convex technology to analyze scope economies. However, as pointed out by Farrell (1959) the convexity assumption precludes any specialization gains in the production technology since any linear and convex combination of two production plans are inefficient relative to a convex isoquant. DEA models are therefore useless in analyzing diseconomies of scope.

Our study moves away from previous papers by estimating the potential gains from specialization under non-convex technologies. While the FDH technology could be used to measure the technical inefficiency, an additivity assumption is required to analyze the optimal reapportionment of activities to smaller units. Hence, the FCH model developed by GC 
(2004) is the relevant candidate. However the overall inefficiency measured relative to the FCH technology comprises three distinct components: technical inefficiency, size inefficiency, and specialization inefficiency. The technical inefficiency could be understood as the inefficiency of a DMU compared to one other DMU with the same degree of specialization. In this case, neither size nor specialization effects are included in the inefficiency measure. Thus, FDH is the relevant technology to compute technical inefficiency. The size inefficiency could be understood as the gain of splitting the activities among smaller units with the same degree of specialization. An FCH model with a pps restricted to DMUs no more specialized than the evaluated one could reveal the size inefficiency. Since the FDH technology is a special case of the FCH technology (see GC, 2004), the FCH inefficiency measure includes the technical inefficiency. Therefore, the difference between the FCH score with the previous FDH score reveals the size inefficiency net of the technical inefficiency. Finally, by comparing an FCH model with a production set containing all DMUs to the latter model, the net effect of the potential gains in specialization is revealed since the technical and size inefficiencies are neutralized.

One main feature of our approach is to consider limited specialization specific to each DMU. While the Panzar and Willig (1981) definition of economies of scope considers the comparison of the cost of joint production to the cost of fully specialized units, we allow a "continuum" in the degree of specialization. Evaluated DMUs are compared to more or less specialized DMUs regarding a degree of specialization that will be defined later. Except for a few studies (e.g., Kim et al., 2005), limited specialization is neglected in the literature. We also contribute to this literature by computing gains issued from comparisons to more and more specialized units in order to measure the returns to specialization in the same spirit that returns to scale are defined.

An illustration is provided using a sample of French farms. The choice of the agricultural sector is motivated by the deep mutations and structural changes caused by successive reforms of the Common Agricultural Policy (CAP). Over the last twenty years, both concentration and specialization of farms were observed in the crop and livestock sectors. Specialization on crops has occurred due to rising costs in livestock production and a decrease of farmers' income related to the new CAP orientations. While most of the previous literature has addressed the question of economies of scope (see among others, Fernandez-Cornejo et 
al., 1992; Chavas and Aliber, 1993 or Wu and Prato, 2006), we depart here by explicitly considering potential gains from specialization.

The remainder of the paper is structured as follows. The methodology developed to compute potential gains from specialization, size, and technical efficiency is presented in the next section. The data used in our empirical analysis and the results are discussed in next to last section. Concluding remarks are presented in the final section.

\section{Methodology}

\subsection{Model}

Suppose we observe $K$ DMUs. Consider a DMU facing a production process with $M$ outputs and $N$ inputs where $y=\left(y_{1}, \ldots, y_{M}\right) \in R_{+}^{M}$ is the vector of outputs and $x=\left(x_{1}, \ldots, x_{N}\right) \in R_{+}^{N}$ is the vector of inputs. We consider different types of technologies by varying the assumptions on additivity (FDH or FCH technologies) and by varying the types of DMUs entering into the production set (all DMUs or some subset of more or less specialized DMUs). By denoting $s=\mathrm{FDH}$ or FCH and $r=$ all DMUs or less/equally specialized DMUs, let $T(s, r)$ be the production set satisfying free disposability of inputs and outputs. We adopt the standard assumption that all DMUs belonging to the production possibility set $T(s, r)$ face the same technology. $T(s, r)$ can be represented by:

$$
T(s, r)=\left\{(x, y): \sum_{k \in K(r)} \lambda^{k} y_{m}^{k} \geq y_{m}, \forall m \in M, \sum_{k \in K(r)} \lambda^{k} x_{n}^{k} \leq x_{n}, \forall n \in N, \lambda^{k} \in \Lambda(s) \forall k \in K(r)\right\}
$$

In (1), $\lambda^{k} \in \Lambda(s)=$ :

$$
\begin{aligned}
& \lambda^{k} \in\{0,1\} ; \sum \lambda^{k}=1 \forall k \in K(r)(\text { for } s=\mathrm{FDH}) \\
& \lambda^{k} \in\{0,1\} \forall k \in K(r)(\text { for } s=\mathrm{FCH})
\end{aligned}
$$

GC (2004) extended the FDH model by introducing the additivity assumption. In contrast with the FDH model, the FCH reference set of an evaluated DMU is no longer restricted to a single observed DMU. The evaluated DMU can be compared to the sum of many other observations. Hence, $T(\mathrm{FDH}, r) \subseteq T(\mathrm{FCH}, r)$. 
By defining $H(k)$ as the degree of specialization of DMU $k$ and by denoting $\bar{H}$ as a prespecified degree of specialization, $K(r)=$ :

$$
\begin{aligned}
& k \in K: H(k) \geq 0 \quad(\text { for } r=\text { all }) \\
& k \in K: H(k) \leq \bar{H} \text { (for } r=\text { less/equally specialized). }
\end{aligned}
$$

The meaning of "all" and "less" is now clear: $K$ (all) contains all observed DMUs in the data set while $K$ (less/equally specialized) contains only the observed DMUs that are equally or less specialized than a chosen level $\bar{H}$.

We now define indices of specialization as traditional Herfindahl-Hirschman concentration indices: $H(k)=\sum_{m \in M} p_{k, m}^{2}$ where $p_{k, m}=\frac{y_{m}^{k}}{\sum_{m \in M} y_{m}^{k}} . H(k)$ is the Herfindahl-Hirschman index of DMU $k$ interpreted as a measure of the degree of specialization of each DMU. We also define $\bar{H}=\sum_{m \in M} p_{j, m}^{2}$ as the Herfindahl-Hirschman index of the evaluated DMU $j$.

We note that Herfindahl-Hirschman indices can be readily used to describe the degree of specialization if the outputs are expressed in the same units of measure. Obviously, this is the case when outputs are revenues from each activity. However, when outputs are defined in different units of measure, the Herfindahl-Hirschman index cannot be directly applied. In this case, revenue shares of activities can be the basis for computing the index. Finally, if output prices are not available, another solution is to use the cost shares of activities derived from the cost accounting of DMUs. While we find Herfindahl-Hirschman indices relevant for measuring the degree of specialization, our approach does not preclude using some other measure.

Given the definitions of technology above, we now present the directional distance function that is used to determine the efficiency with which technology is utilized. Whereas GC (2004) used an input-oriented radial efficiency measure, we employ an input directional distance function in order to allow the addition of efficiency scores among groups of DMUs or among the whole sample. The function $\vec{D}_{T(s, r)}:\left(R_{+}^{M} \times R_{+}^{N}\right) \times R_{+}^{N} \longrightarrow R_{+}$defined by:

$$
\vec{D}_{T(s, r)}(x, y ; g)=\sup _{\delta}\left\{\delta \in R_{+}:(x-\delta g, y) \in T(s, r)\right\}
$$


is the input distance function in the direction $g$. An analysis of the properties of the directional distance function can be found in Chambers et al. (1996).

The inefficiency of DMU $j$ is evaluated by the following program:

$$
\begin{aligned}
& \vec{D}_{T(s, r)}\left(x^{j}, y^{j} ; g\right)=\max _{\delta, \lambda} \delta \\
& \text { s.t. } \\
& \sum_{k \in K(r)} \lambda^{k} y_{m}^{k} \geq y_{m}^{j} \quad \forall m \in M \\
& \sum_{k \in K(r)} \lambda^{k} x_{n}^{k} \leq x_{n}^{j}-\delta g_{n} \quad \forall n \in N \\
& \lambda^{k} \in \Lambda(s) \quad \forall k \in K(r)
\end{aligned}
$$

where $\delta$ measures the maximal reduction of inputs to reach the frontier. If $\delta=0$, the evaluated DMU is efficient.

When based on the most general pps (where $s=\mathrm{FCH}$ and $r=$ all), the inefficiency score $\vec{D}_{T(\mathrm{FCH}, \text { all })}$ includes several components, namely technical, size, and specialization inefficiencies. Indeed, an inefficient DMU could be compared to a more efficient DMU of the same size and with the same degree of specialization and the inefficiency score then could be interpreted as consisting of only technical inefficiency. It could also be the case that the evaluated DMU is found inefficient relative to a sum of smaller but less or equally specialized DMUs. In this case, the inefficiency would be the result of a size effect. It is important to note that we consider the size inefficiency in the spirit of Maindiratta (1990), rather than as the traditional measure of scale inefficiency. The assumption of divisibility is not considered in our approach, thus precluding any measure of scale inefficiency based on the most productive scale size (MPSS) concept (Banker, 1984). However, the additivity assumption of FCH allows for the comparison of a large DMU to the sum of smaller ones and hence reveals any size inefficiency. Finally, if the reference set of the evaluated DMU is composed of more specialized DMUs, then the inefficiency can be viewed as a potential gain in specialization. Whereas one, two, or three of these components can coexist in the overall efficiency score, it seems useful to decompose the overall efficiency into its technical, size, and specialization 
effects. This can be done by both selecting the appropriate technology and exploiting the link between the FDH and FCH models.

The technical inefficiency of DMU $j$ is obtained by solving program (3) with $s=$ FDH and $r=$ less/equally specialized (denoted $\vec{D}_{T(\mathrm{FDH}, \text { less })}$ ). By avoiding the additivity assumption and by restricting the pps to include only less or equally specialized DMUs, neither size effect nor specialization gains can be the sources of the inefficiency. Therefore, only technical inefficiency effect is present in this restricted model.

To assess size inefficiency, we need to compare the evaluated DMU to smaller ones. Therefore, by considering $s=\mathrm{FCH}$ and $r=$ less/equally specialized, $\vec{D}_{T(\mathrm{FCH}, \text { less })}$ adds the size inefficiency of DMU $j$ to the FDH score. Now by comparing the two efficiency scores $\vec{D}_{T(\mathrm{FCH}, \text { less })}$ and $\vec{D}_{T(\mathrm{FDH}, \text { less })}$, we can measure the net effect of size inefficiency. As shown by GC (2004), the inefficiency score obtained under FDH is always less than or equal to the inefficiency score under FCH. Thus:

(i) if $\vec{D}_{T(\mathrm{FCH}, \text { less })}-\vec{D}_{T(\mathrm{FDH}, \text { less })}=0$ then DMU $j$ operates at the most efficient size of production. Here, no gain is possible by varying size.

(ii) if $\vec{D}_{T(\mathrm{FCH}, \text { less })}-\vec{D}_{T(\mathrm{FDH}, \text { less })}>0$ then DMU $j$ can increase its productivity by splitting its production among smaller units.

Next, gains from specialization are measured by comparing the efficiency scores $\vec{D}_{T(\mathrm{FCH}, \text { all })}$ and $\vec{D}_{T(\mathrm{FCH}, \text { less })}$. Again, the same logic is used here-the technologies $T(\mathrm{FCH}$, all $)$ and $T(\mathrm{FCH}$, less $)$ differ only with respect to the specialization of the DMUs included in the pps. By evaluating a DMU relative to less or equally specialized DMUs and then relative to all DMUs (including the more specialized ones), the potential gains from specialization are given by difference in the resulting efficiency scores. Since $T(\mathrm{FCH}$, all $) \subseteq T(\mathrm{FCH}$, less $)$, two possible cases arise:

(i) if $\vec{D}_{T(\mathrm{FCH}, \text { all })}-\vec{D}_{T(\mathrm{FCH}, \text { less })}=0$, then there is no gain from specialization.

(ii) if $\vec{D}_{T(\mathrm{FCH}, \text { all })}-\vec{D}_{T(\mathrm{FCH}, \text { less })}>0$, then the difference indicates input reductions which can be obtained by specialization. 
Finally, we have the following decomposition of the overall efficiency measure into its three components:

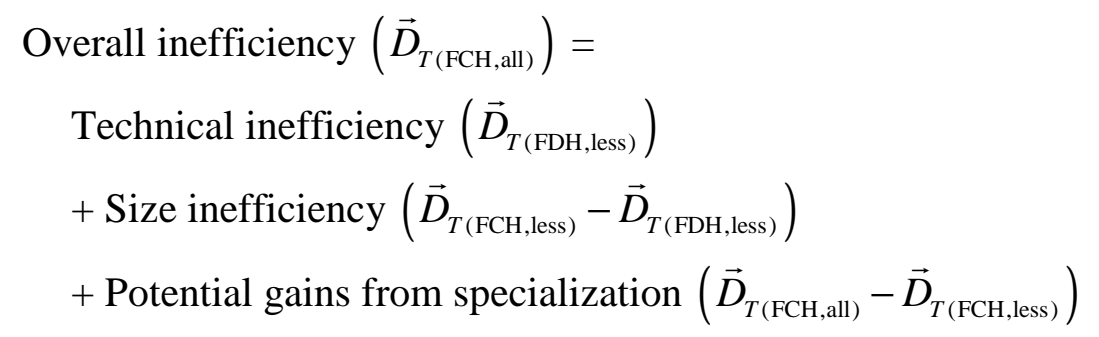

\subsection{A numerical example}

To illustrate the approach presented above, consider a simple example with six DMUs which produce two outputs, $y_{1}$ and $y_{2}$, from one input, $x$. Table 1 presents the data used for this example.

Table 1 Numerical example - Data -

\begin{tabular}{lcccccc}
\hline & DMU a DMU b DMU c & DMU d & DMU e DMU f \\
\hline$y_{1}$ & 60 & 62 & 24 & 45 & 10 & 50 \\
$y_{2}$ & 40 & 43 & 16 & 30 & 30 & 12 \\
$x$ & 20 & 19 & 7 & 10 & 7 & 7 \\
Herfindahl-Hirschman index & 0.520 & 0.516 & 0.520 & 0.520 & 0.625 & 0.688 \\
\hline
\end{tabular}

First consider the evaluation of the DMU $a$. Compared to DMU $a$ (which has a specialization index of 0.52 ), DMU $b$ has quite the same size and is a little bit less specialized. Therefore a comparison between DMUs $a$ and $b$ can only reveal the technical inefficiency of DMU $a$. DMU $c$ and DMU $d$ have the same level of specialization as DMU $a$, but they are smaller than DMU $a$. Hence, a comparison of DMU $a$ to DMUs $c$ and $d$ cannot reveal specialization gain but can indicate size inefficiency under the FCH model. The two last DMUs, $e$ and $f$, are smaller and more specialized. Thus, the comparison of the FDH and FCH models can reveal net gains from specialization. Table 2 summarizes the results for DMU $a$.

Table 2 Simple numerical example - Results for DMU $a$ -

\begin{tabular}{ccccc}
\hline & $\begin{array}{c}\text { Overall } \\
\text { Inefficiency }\end{array}$ & $\begin{array}{c}\text { Technical } \\
\text { Inefficiency }\end{array}$ & $\begin{array}{c}\text { Size } \\
\text { Inefficiency }\end{array}$ & $\begin{array}{c}\text { Specialization } \\
\text { Inefficiency }\end{array}$ \\
\hline DMU $\boldsymbol{a}$ & 0.300 & 0.050 & 0.100 & 0.150 \\
\hline
\end{tabular}




\subsection{Benchmark selection}

To evaluate specialization gains as a function of the degree of specialization, we evaluate DMU $j$ relative to different technologies composed of more and more specialized DMUs. In contrast to almost all published cases, we do not arbitrarily partition the sample into subsamples of specialized and diversified units by imposing a unique and exogenous rate of specialization. Instead, we consider a relative level of specialization for each evaluated DMU rather than an absolute level. Except for DMUs that are fully specialized, gains from specialization could be found even for highly specialized DMUs.

Formally, for each DMU, we consider various pps with variable subgroups of DMUs $K(\tau)=\{k \in K \mid H(k) \leq \bar{H}+\tau\}$, where $\bar{H}$ is the Herfindahl index of the evaluated DMU and $\tau$ is the additional degree of specialization. Therefore, as $\tau$ increases, more and more DMUs belong to the pps of the evaluated DMU and the latter is compared to increasingly specialized DMUs. Obviously, $K(\tau=0)=K$ (less/equally specialized) and the reference set is composed of only the less or equally specialized DMUs, as above. The maximal range of variation for $\tau$ depends on the Herfindahl-Hirschman index observed in the data, and $\tau \in\left[0,1-\frac{1}{M}\right]$ since the minimal value for a Herfindahl-Hirschman index is $\frac{1}{M}$ where $M$ is the number of outputs. Compared to equation (1), we now define the pps $T(s, \tau)$ as follows:

$$
T(s, \tau)=\left\{(x, y): \sum_{k \in K(\tau)} \lambda^{k} y_{m}^{k} \geq y_{m}, m=1, \ldots, M, \sum_{k \in K(\tau)}^{K} \lambda^{k} x_{n}^{k} \leq x_{n}, n=1, \ldots, N, \lambda^{k} \in\{0,1\}\right\}
$$

By varying $\tau$ from 0 to $(1-\bar{H})$, we can compute specialization gains issuing from comparisons to more and more specialized DMUs. 


\section{Empirical application}

\subsection{Data}

The sample used in our empirical application of the methods presented above is composed of 609 farms observed in the year 2003. The farms are located in the French "département de la Meuse", an area situated in the northeast of France. Outputs consist of the revenues generated by crops (wheat, barley, peas, etc.), livestock (milk and cattle), and other production (other agricultural work, annex and residual products, etc.). We use the total cost of production as the input. It is composed as follows: (i) intermediate consumption included operational expenses (fertilizer, seeds, pesticide) and other costs (fuel, water, etc.); (ii) cost of surface area computed by applying rental rates to both hired and owned land; (iii) taxes and salaries of hired labor expressed as full time equivalency farm employees and the cost of family labor; and (iv) cost of capital, including machinery and building expenses.

Descriptive statistics of the output and input data appear in Table 3. According to the minimum values observed over the sample, the data contain fully specialized farms in the two main outputs (livestock and crops). By contrast, all farms produce at least some other production. The data also present some variability in the size of farms, as demonstrated by the large standard deviations (compared to the means). The Herfindahl-Hirschman indices reveal the presence of perfectly diversified farms $(\mathrm{H}=1 / \mathrm{M}=0.33)$ and quasi fully specialized farms $(\mathrm{H}=0.96 \approx 1)$.

Table 3 Descriptive statistics

\begin{tabular}{|c|c|c|c|c|}
\hline & Mean & $\begin{array}{l}\text { Standard } \\
\text { deviation }\end{array}$ & Min & $\operatorname{Max}$ \\
\hline \multicolumn{5}{|l|}{ Output (in Euros) } \\
\hline Crops & 49657 & 44223 & 0 & 331399 \\
\hline Livestock & 106581 & 88213 & 0 & 557360 \\
\hline Other production & 32498 & 49498 & 1209 & 865200 \\
\hline \multicolumn{5}{|l|}{ Input (in Euros) } \\
\hline Cost of immobilizations & 191258 & 115171 & 37341 & 1026478 \\
\hline Herfindahl-Hirschman index & 0.55 & 0.14 & 0.33 & 0.96 \\
\hline
\end{tabular}




\subsection{Results}

Table 4 reports the potential cost reductions and the number of inefficient farms for each efficiency type. On average, farms could reduce their total cost by up to $21.3 \%$ by reducing technical, size, and specialization inefficiencies. In other words, if all farms had operated on the production frontier, they could reduce their cost by $21.3 \%$, holding output level constant. As a result of the decomposition of overall inefficiency presented above, we note that the potential gains from specialization could reduce cost by nearly $10 \%$. By eliminating mismanagement of resource (technical inefficiency) total cost could be reduced by $2.8 \%$ and a further $8.6 \%$ cost reduction is possible if operating at the optimal size. However, the main source of inefficiency is related to diseconomies of scope and $47 \%$ of overall inefficiency is due to the specialization inefficiency. A large majority of farms (531 farms-87\%) exhibit at least one form of inefficiency and $71 \%$ of them could benefit from cost reduction by increasing their specialization. Thus, specialization is again the main source of potential gains.

Table 4 Overall, specialization, size and technical inefficiency measures

\begin{tabular}{lcccc}
\hline & $\begin{array}{c}\text { Overall } \\
\text { inefficiency }\end{array}$ & $\begin{array}{c}\text { Technical } \\
\text { inefficiency }\end{array}$ & $\begin{array}{c}\text { Size } \\
\text { inefficiency }\end{array}$ & $\begin{array}{c}\text { Specialization } \\
\text { inefficiency }\end{array}$ \\
\hline \% of potential reduction in total cost & 21.3 & 2.8 & 8.6 & 9.9 \\
\% in overall efficiency & 100 & 13 & 40 & 47 \\
Number of inefficient farms & 531 & 184 & 365 & 435 \\
\% in total sample & 87 & 30 & 60 & 71 \\
\hline
\end{tabular}

To better illustrate the insights gained from our approach, results are detailed for three representative cases. In Table 5, we consider for the evaluated farms $a, b$, and $c$ the revenue shares of each output and their respective optimal reference set when computing the specialization inefficiency. Farm $a$ produces both crops and livestock and appears to be unspecialized (Herfindahl-Hirschman index $=0.38$ ). Under the FCH model, farm $a$ is compared to the sum of two farms, $a 1$ and $a 2$, which, respectively, specialized in crops and livestock. This is a typical case where an efficiency gain could be made by splitting a mixed production unit into two specialized units. The case of farm $b$ (Herfindahl-Hirschman index $=$ 0.74) highlights that our approach does not preclude specialization gains even for initially highly specialized farms. Furthermore, consider the case of farm $c$ which has four referents (farms $c 1, c 2, c 3$ and $c 4$ ). As noted by GC (2004), the reorganization can become more 
complex when inefficient farms, such as farm $c$, have reference set cardinalities greater than two.

Table 5 Detailed results for three illustrative farms

\begin{tabular}{|c|c|c|c|c|c|}
\hline & & $\begin{array}{c}\text { Herfindahl- } \\
\text { Hirschman } \\
\text { index }\end{array}$ & Crops & Livestock & $\begin{array}{c}\text { Other } \\
\text { production }\end{array}$ \\
\hline \multirow{4}{*}{$\begin{array}{l}\text { Evaluated } \\
\text { Referents }\end{array}$} & farm $a$ & 0.38 & $35 \%$ & $48 \%$ & $17 \%$ \\
\hline & & & & & \\
\hline & farm $a 1$ & 0.62 & $75 \%$ & $0 \%$ & $25 \%$ \\
\hline & farm $a 2$ & 0.76 & $5 \%$ & $87 \%$ & $8 \%$ \\
\hline \multirow{4}{*}{$\begin{array}{l}\text { Evaluated } \\
\text { Referents }\end{array}$} & farm $b$ & 0.74 & $85 \%$ & $0 \%$ & $15 \%$ \\
\hline & & & & & \\
\hline & farm $b 1$ & 0.78 & $88 \%$ & $0 \%$ & $12 \%$ \\
\hline & farm $b 2$ & 0.62 & $75 \%$ & $0 \%$ & $25 \%$ \\
\hline \multirow{6}{*}{$\begin{array}{l}\text { Evaluated } \\
\text { Referents }\end{array}$} & farm $c$ & 0.65 & $78 \%$ & $0 \%$ & $22 \%$ \\
\hline & & & & & \\
\hline & farm $c 1$ & 0.58 & $70 \%$ & $0 \%$ & $30 \%$ \\
\hline & $\operatorname{farm} c 2$ & 0.79 & $88 \%$ & $0 \%$ & $12 \%$ \\
\hline & farm $c 3$ & 0.84 & $91 \%$ & $0 \%$ & $9 \%$ \\
\hline & farm $c 4$ & 0.62 & $75 \%$ & $0 \%$ & $25 \%$ \\
\hline
\end{tabular}

Table 6 shows the cardinality of the reference sets of inefficient farms with regards to the specialization component. Among the inefficient farms (435 farms out of 609), we note that the reference set comprises from 1 to 8 farms. However, $79 \%$ of farms have a reference set composed of three or fewer farms. Following GC (2004), we could have easily restricted the number of referents by introducing a constraint into LP (3). As a by-product, this could lead to an analysis of specialization gains as a function of number of referents. Indeed, it is not necessary to have a complex reapportionment of the activities if, for example, $90 \%$ of the specialization gains could be realized by splitting the production among only two farms. 
Table 6 Cardinality of reference sets of inefficient farms

\begin{tabular}{cccc}
\hline \# referents & \# cases & \% & cumulated \% \\
\hline 1 & 10 & 2 & \\
2 & 189 & 43 & 2 \\
3 & 144 & 33 & 46 \\
4 & 53 & 12 & 79 \\
5 & 23 & 5 & 91 \\
6 & 10 & 2 & 96 \\
7 & 2 & 0 & 99 \\
8 & 4 & 1 & 99 \\
\hline Total & 435 & 100 & 100 \\
\hline
\end{tabular}

Finally, we are interested in the returns to specialization. In other words, we analyze whether full specialization is necessary to achieve the bulk of the specialization gains. We therefore compute the reduction in total cost obtained from a limited amount of specialization to full specialization. We consider the pps defined in equation (5) with $\tau$ varying by steps of $5 \%$; i.e., $\tau \in\{5 \%, 10 \%, 15 \%, 20 \%, \ldots\}$. In other words, we add to the pps of the evaluated farm, farms with increasingly higher Herfindahl-Hirschman indices. Since the production technology is based on three outputs (crops, livestock, and other production), we have $\tau_{\max }=66.7 \%$. Figure 1 plots the results.

Figure 1: Percentage of reduction in total cost by increasing the specialization

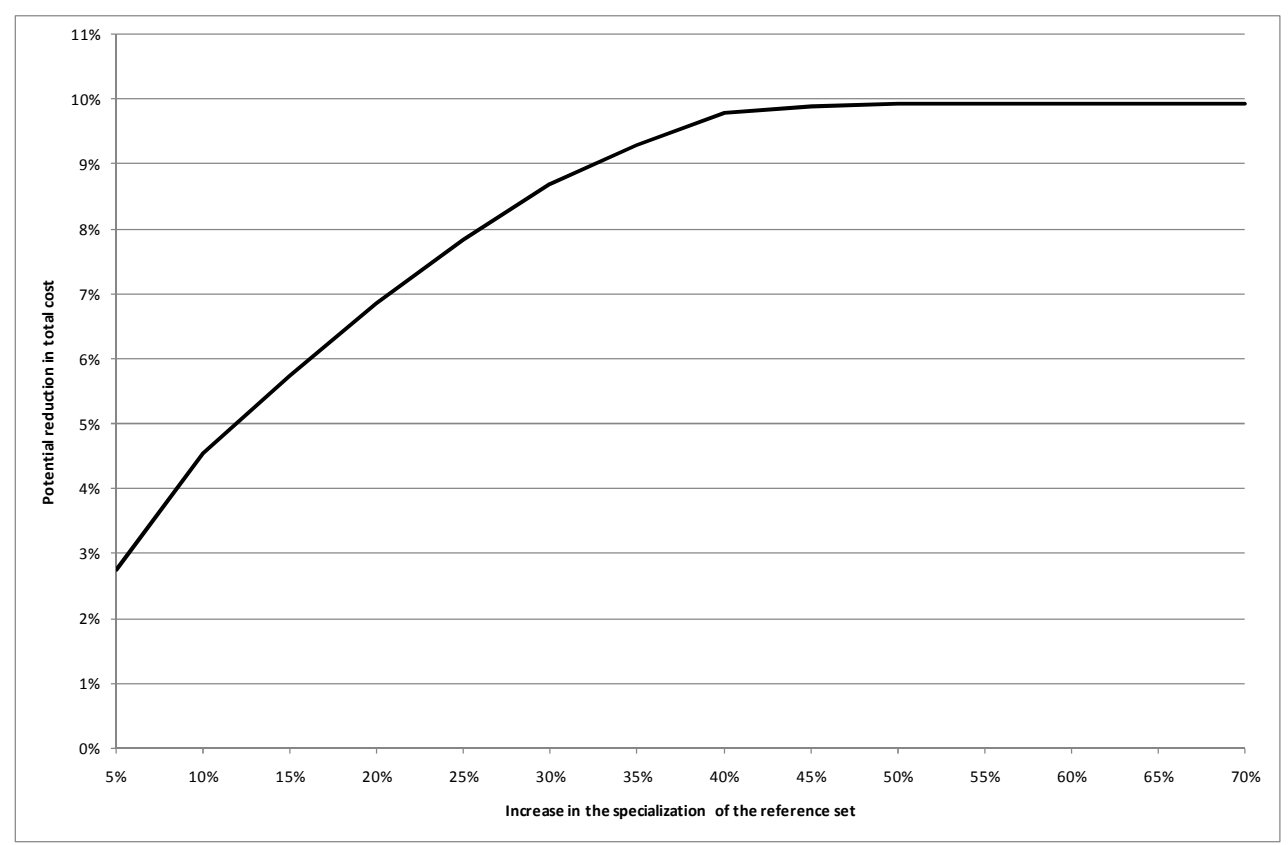


Gains steadily increase with the addition of more specialized farms with HerfindahlHirschman indices up to $40 \%$; further gains beyond this level of specialization are slight. This result suggests that for a majority of farms, full specialization is not necessary to realize potential specialization gains. As a result, we find decreasing returns to specialization gains.

\section{Concluding remarks}

As suggested by Green and Cook (2004), the Free Coordination Hull (FCH) model provides new opportunities for empirical analyses. In this contribution, we have focused on diseconomies of scope and we have proposed a methodology to measure potential gains from specialization under non-convex technologies. An illustration for the French agricultural sector has been presented. Our results reveal that the main source of reduction in total cost is an increase in the specialization of farms in terms of crops or livestock production. This could partly explain the increasingly heavy tendency of concentration and specialization observed in the French agricultural sector over the last twenty years.

\section{References}

Banker R. D (1984) Estimating most productive scale size using data envelopment analysis. European J. Oper Res 17: 35-44.

Baumol JW, Panzar JC and Willig RD (1982). Contestable markets and the theory of industry structure. New York: Harcourt, Brace and Jovanovich (eds).

Bogetoft P and Wang D (2005). Estimating the potential gains from mergers. J Prod Anal 23: 145-171.

Chambers RG, Chung Y and Färe R (1996). Benefit and distance function. J Econ Theory 70: 407-419.

Chavas JP and Aliber M (1993). An analysis of economic efficiency in agriculture: a nonparametric approach. J Agr Resource Econ 18(1): 1-16.

Deprins D, Simar L and Tulkens H (1984). Measuring labor efficiency in post offices. In: Marchand M, Pestieau $\mathrm{P}$ and Tulkens $\mathrm{H}$ (eds.), The performance of public enterprises concepts and measurements. Elsevier, Amsterdam.

Färe R (1986). Addition and efficiency. Quart J Econ 101: 861-866.

Farrell MJ (1959). The convexity assumption in the theory of competitive markets. J Polit Economy 67(4):377-391. 
Fernandez-Cornejo J, Gempesaw II CM, Elterich JG and Stefanou SE (1992). Dynamic measures of scope and scale economies: an application to German agriculture. Amer J Agr Econ 74, 329-342.

Green RH and Cook WD (2004). A free coordination hull approach to efficiency measurement. J Opl Res Soc 55: 1059-1063.

Grosskopf S and Yaisawarng S (1990). Economies of scope in the provision of local public service. Nat Tax J 43(1): 61-74.

Kim K, Barham B, Chavas JP and Foltz J (2005). Research and development at U.S. research universities: an analysis of scope economies. Staff Paper $n^{\circ} 487$, University of WisconsinMadison, $43 \mathrm{p}$.

Maindiratta A (1990). Largest size-efficient scale and size efficiencies of decision-making units in Data Envelopment Analysis, J Econometrics 46:57-72.

Panzar JC and Willig RD (1981). Economies of scope. Amer Econ Rev 71: 268-272.

Wu S and Prato T (2006). Cost efficiency and scope economies of crop and livestock farms in Missouri. J Agr Appl Econ 38(3): 539-553. 